easily changed. The sexual polarisation of doctor-tophysiotherapist (like doctor-to-nurse) intensified the apparent subservience of one to the other, but it would be naive to accept this at its face value. Elements of excitement and satisfaction as well as rivalry and ensnarement complicate the collaboration. Sometimes physiotherapists seem like little girls worshipping their big brothers, locked in rivalry with the nurses, social workers, and occupational therapists for the position of favourite -be it favourite wife or favourite child-or even for some excitement as "the other woman" in a triangle. At other times they appear to indulge the vanity of their doctors, colluding with every kind of nonsense like doting mothers reluctant to interrupt the imaginative games of their little boys. To tell the great neurologist that his electrical treatment for Bell's palsy is wasting everyone's time might be like calling in the Duke of Wellington to clean his teeth before bedtime.

Nevertheless, an undercurrent of genuine satisfaction in legitimate professional sublimation of sexual roles may serve to make intolerable conditions tolerable, and the seminar could not afford to promote cheap debunking. We could sometimes see how seemingly stupid situations had become stuck, but we learnt to become cautious before scoffing at the anachronisms in which medical work is embedded. Other beds may prove worse. Describing the difficulties of physiotherapists and some tough lessons for doctors should not hide the professional and personal satisfaction shared in struggling alongside one another. Throughout our ups and downs and many fraught periods of work I was astonished and captivated by the grit, humour, empathy, ingenuity, and feminine grace that pervaded this group.

This work was assisted by a generous grant from Update Publications.

\section{References}

${ }^{1}$ Bourne, S, and Lewis, E, Medical Education, 1978, 12, 344.

' Gosling, R, and Turquet, P M, The Use of Small Groups in Training, p 13. London, Codicote Press, 1967.

Balint, M, The Doctor, His Patient and the Illness. London, Pitman, 1957.

4 Bourne, S, Psychiatria Fennica, 1975, p 339.

'Bourne, S, Fournal of the Royal College of General Practitioners, 1976, 26, 487.

"Department of Health and Social Security, Rehabilitation: Report of a Sub-Committee of the Standing Medical Advisory Committee. London, HMSO, 1972.

' Department of Health and Social Security, The Remedial Professions. London, HMSO, 1973.

Glossop E S, Hospital Update, October 1977, p 593.

${ }^{9}$ Norman, P, et al, British Medical fournal, 1975, 4, 220.

(Accepted 14 September 1978)

\title{
How should a consultant spend his time?
}

\author{
T LESLIE DUNN, DAVID J ATTWOOD
}

British Medical fournal, 1978, 2, 1763-1765

\section{Summary and conclusions}

The activities of a whole-time consultant psychiatrist with clinical, teaching, and administrative responsibilities were analysed over six weeks. With the exclusion of time spent on call at night and weekends he worked an average of $57 \cdot 4$ hours a week. Altogether $42.3 \%$ of his time was spent on clinical work, $25.5 \%$ on general administration, and $24.0 \%$ on tutorial activities. Although he discharged his duties as well as might reasonably be expected, his clinical work was thought to have suffered.

Postgraduate activities and medical administration are important in the ultimate care of patients, but the structure of the National Health Service does not enable a consultant to meet all these demands adequately.

\section{Introduction}

Apart from figures based on personal estimates' little information is available on how consultants in the National Health Service use their time. With the growth of postgraduate education, particularly in "non-teaching" hospitals, and the increasing

Central Hospital, Hatton, Warwick CV35 7EE

T LESLIE DUNN, MRCP, FRCPSYCH, consultant psychratrist

West Midland Regional Health Authority

DAVID J ATTWOOD, MWsom, management services officer participation in administration the demands on consultants often conflict with their primary function-namely, the care of patients. Two reports, ${ }^{3} 3$ however, have emphasised the importance of the doctor's role in management.

This inquiry was designed to see how a whole-time consultant psychiatrist spent his time over six weeks. While patterns of work in different specialties vary, all embrace clinical, administrative, and teaching components. Psychiatrists, however, have also had to cope with changing concepts of practice, particularly over the past decade or so. These include providing services in the community, often some distance from the parent hospital, and the transition: from inpatient services based in the old county mental hospitals to new psychiatric units in district general hospitals.

The clinical commitment of the consultant was similar to that of many psychiatrists and comprised responsibility for about two-thirds of a mixed urban and rural population of some 83000 focused on Rugby as well as overall administrative responsibility for the area service as a whole. Outpatient care was provided at the Hospital of St Cross, Rugby; inpatient facilities were available at the local psychiatric hospital-Central Hospital, Warwick-20 miles ( $32 \mathrm{~km}$ ) away, and a new district general hospital-Walsgrave Hospital, Coventry-some 15 miles $(24 \mathrm{~km})$ away. The consultant was also a Universityappointed clinical tutor, for both the psychiatric and district general hospitals, and in April 1972 undertook chairmanship of the district general hospital's psychiatric division-one of two Cogwheel divisions with which he was concerned.

In view of the large amount of time that he was spending on administration he asked the management services division of the then Birmingham Regional Board to analyse the pattern of his work to see whether his time could be used more efficiently. A management services officer was assigned. 


\section{Methods and results}

During one week in May 1972, which was included in the final analysis, the management services officer recorded the consultant's daily activities. This allowed the three main areas of work to be identified-namely, clinical, tutorial, and general administrative-and formed the basis of a further five weeks' recording in October (see figure). Some of this second recording was carried out by the consultant. Most members of staff on whom the consultant's work impinged were interviewed. These included consultant colleagues, resident medical staff, nurses, social workers, and psychologists as well as members of the various administrations, including hospital secretaries and divisional secretaries. Personal secretaries were also seen. This was to find how the way in which the consultant worked affected other members of the system and the services provided. Patients were not included.

With the exclusion of time spent on call at night and weekends the consultant worked an average of $\mathbf{5 7 . 4}$ hours a week. This figure was derived from 29 days worked out of a possible 33, four days' leave being taken.

\section{CLINICAL WORK}

A total of $42.3 \%$ of the consultant's time was spent on clinical work (see figure)-namely, personal contact with patients, supervising other members of the medical team, and all work arising from such activities.

New outpatients-The average time spent on each new outpatient referral was 35 minutes. In addition each new outpatient was also seen initially by another doctor in the team. This 35 minutes, however, included presentation by, and subsequent discussion with, the junior doctor, so that the actual time spent by the consultant with the patient averaged well under 35 minutes.

Old outpatients-Out of 69 patients booked to see the consultant personally during the observation period, 57 did so, the average consultation time being about 17 minutes. This is a small amount of time, for many such patients go up to three months between visits. At one clinic 11 out of 12 patients so booked had to be seen by a senior house officer (with a senior registrar available if required) because of the consultant's commitments as divisional chairman. Thus $17 \cdot 4^{\circ}{ }_{0}$ of patients booked to see the consultant personally did not do so owing to administrative duties.

Domiciliary consultations were usually made at the end of the day. A total of 3.3 hours was spent in direct contact with patients-that is,
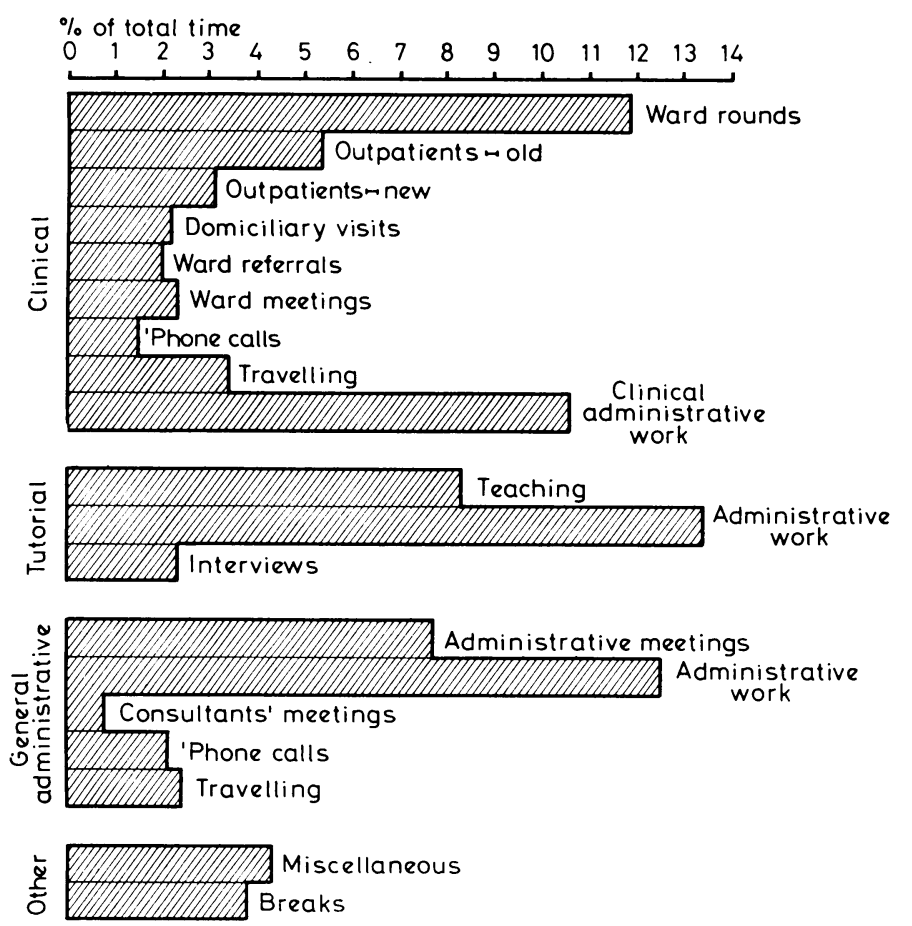

Proportions of total time spent by consultant on various activities over six weeks. (Excludes time spent on call at night and weekends.) an average of just over 20 minutes in each case, and somewhat, less than the time taken in getting there.

Ward rounds were conducted weekly. At the district general hospital patients with acute disorders were given about 18 minutes a week each, and those at the psychiatric hospital about 15 minutes a week each. The time spent on long-stay wards-in seven of which the consultant had clinical responsibility for about 175 patients and in four administrative responsibility-averaged about one and a half hours a week. If patients were to be seen individually, this would have been a meaningless half a minute or so a week each. In practice, patients were seen to whom attention was drawn, by either the ward doctor or nursing staff (or occasionally by some other professional or agency), or in whom the consultant was particularly interested. During the observation period many long-stay patients would have had no individual contact with the consultant.

Consultant service to general hospital inpatients-The number of inpatient referrals seen is unknown. Any case referred on the general wards was seen first by a junior psychiatrist, who would make his findings known to the consultant; he would then see the patient briefly, particularly for a quick decision on disposal from an acute bed -usually medical.

Ward meetings were carried out on each admission ward and on a group of long-stay wards and occurred at about monthly intervals or more often if required. These were staff meetings concerned mainly with overall ward policy, but interdisciplinary and interpersonal problems were also dealt with. It was not possible to be present at patient-staff meetings.

Clinical administrative work was mostly correspondence relating to outpatients.

\section{TUTORIAL WORK}

Tutorial activities accounted for $24.0^{\circ}$ of the consultant's time. The work entailed co-ordinating and developing a programme for trainees, teaching, giving individual guidance and counselling, supervising the rotation of trainees and integrating this with service needs, co-ordinating annual and study leave, establishing educational links with outside bodies, and promoting research. Help in the welfare of trainees-for example, with accommodation-was also given. At the time of the survey there were 18 trainees.

\section{GENERAL ADMINISTRATION}

General administration occupied $25.5 \%$ of the consultant's time.

Administrative work included all tasks relating to medical administration not covered by other headings-for example, dealing with correspondence and circulars and day-to-day discussions with administrators.

Administrative meetings included all formal meetings and committees, as well as those related to his divisional chairmanship and being senior psychiatrist in Rugby. Also included were meetings on voluntary projects in the community, liaison with the social services department and local general practitioners, and operational research into the provision of the local mental health services as well as the development of a community psychiatric nursing service.

Consultant meetings were held weekly at the local psychiatric hospital and were informal.

\section{TRAVELLING AND OTHER ACTIVITIES}

Travelling time accounted for $6.9^{\circ}$ of the total time-that is, four hours a week. Other activities included eating, leaving and entering the hospital, etc. Breaks, including meals, averaged 24 minutes a day.

\section{Discussion}

Any such study as this must reflect not only the idiosyncrasies of the consultant concerned but also the nature of his work. This consultant, for example, had major administrative and teaching roles as well as clinical commitments. Discussion with staff whose roles were related to that of the consultant suggested that he was coping as well as might reasonably be expected. Teaching and medical administration were thought to be essential for the functioning of the service and of ultimate 
benefit to patients. Such activities, however, consumed a great deal of time, with the result that time available for clinical work suffered. This is unsatisfactory for the patient and referring agency and poses considerable problems of personal professional conscience for the practitioner.

The amount of time spent on clinical work was 24.3 hours a week. This is interesting when compared with the 39.6 hours of professional time devoted to direct and indirect patient care during a mean working week of 45 hours as reported for surgeons in the USA' and the 39.3 hours out of an average working week of 48.7 hours reported by the Office of Manpower Economics." Though our findings suggest that less paper work might improve the consultant's efficiency, assuming the various tasks to be necessary, no way emerged in which major savings in time could be effected. Adequate secretarial support was found to be important.

\section{Conclusion}

Our findings highlight many of the difficulties facing consultants, particularly that of adequately meeting clinical, administrative, and teaching demands. Medical participation in management is thought to be necessary, but whether the Cogwheel system is the most effective way of achieving this is unresolved. The possibility of a career medical administrator at hospital level with a limited clinical commitment must be considered. Interestingly, community physicians are now analysing and appraising the roles within their discipline. ${ }^{6}$ Similarly, although it is hoped that all consultants will teach their own juniors, there is a need for a tutor at hospital level over and above this. The present system usually allows these timeconsuming management and educational demands to be met in a satisfactory way only at the expense of clinical needs.
The activity analysis described can be a useful management tool for consultants but must take into account the effect of their work on other members of the team. Such analysis should not be imposed and the request should emanate from the consultant. The consultant should also be willing to change his patterns of work. Carried out in this way it can help bridge the gap between the clinician and manager and is particularly valuable in giving the manager insight into the problems of the delivery of health care at day-to-day clinical level with the appreciation that management structures and decisions must be devised to take account of clinical needs and not vice versa.

We are grateful to Dr Christie Gordon, ex-Regional Medical Officer, and $\mathrm{Mr}$ David H Shanks, Regional Management Services Officer, officers of the former Coventry and South Warwickshire Group Hospital Management Committees; the many hospital staff who facilitated this study in various ways; and Mrs Joan Mann for secretarial help.

Requests for reprints should be addressed to Dr T L Dunn, Central Hospital, Hatton, Warwick CV35 7EE.

\section{References}

${ }^{1}$ British Medical Association News Review, 1977, 3, 482.

2 DHSS, First Report of the foint Working Party on the Organisation of Medical Work in Hospitals. London, HMSO, 1967. (Cogwheel Report.)

${ }^{3}$ DHSS, Management Arrangements for the Re-organised National Health Service, pp 66-77. London, HMSO, 1972.

${ }^{4}$ Study on Surgical Services for the United States, Summary Report, $11 / 18 / 74$.

5 Review Body on Doctors' and Dentists' Remuneration, 8th Report, Cmnd 7176, Appendix D, Table 2, p 80. London, HMSO, 1978.

${ }^{6}$ British Medical Association News Review, 1978, 4, 43.

(Accepted 9 October 1978)
What disinfectant should be used in a domestic shower to prevent the spread of fungal infection such as athlete's foot?

The floor covering in the immediate vicinity of the shower itself should be wiped with a suitably diluted liquid household detergent. The floor of the shower itself should be thoroughly rinsed after the individual suspected of shedding infected skin scales has used it. A few drops of a liquid household detergent would make it more effective. Any rubber mats, whether on the floor of the shower or in the bathroom, must be scrubbed with a detergent solution, using in addition, at least twice a week, a potent household disinfectant and cleansing powder such as Ajax or Vim. The mats should then be hung up and allowed to dry. If mats made of cotton or some other material or man-made woven thread are used the suspected carrier of a fungal infection should have his individual mat.

Symptoms in malaria are said to be related to release of merozoites from the erythrocytes, yet the associated fever may exhibit a tertian or quartan pattern. How is the release of the parasites synchronised to cause this pattern of fever?

There is still no certain information on the way in which the release of malaria parasites is synchronised, and the mechanism causing the fever also poses problems. The development of immunity by a patient is probably responsible for eliminating subsidiary strains of the parasite and thus leaving the patient with only one strain with its basic 48 - or 72 -hour cycle.

What treatment, including diet, is advisable for a patient with diverticulitis?

Most patients with symptoms (such as pain and disturbed bowel habit) associated with colonic diverticula have no inflammation in those diverticula, and the condition is currently referred to as diverticular disease. As infection plays no part, antibiotics are not advised. A high- fibre diet, supplemented for a few weeks with hydrophilic preparations such as methylcellulose, usually relieves the symptoms. Occasionally a diverticulum does become infected, causing "true" diverticulitis or a peridiverticular abscess, with pyrexia, leucocytosis, and usually considerable tenderness. Conservative treatment (bed rest, low-fibre diet to reduce colonic muscular activity, and antibiotics-such as gentamicin and metronidazole) may be successful, but if evidence of inflammation persists surgical drainage of the abscess is required.

A patient aged 36 has had a hysterectomy and bilateral oophorectomy for benign ovarian cysts. She is having to take oestrogenic substances (Premarin) for severe hot flushes. This is proving satisfactory, but a television programme suggested that this type of treatment, without intermittent treatment with a progestogen, might result in carcinoma of the breast. Is this so and, if so, what drug should be given?

It is still not possible to be dogmatic about the relationship of unopposed oestrogen treatment and carcinoma of the breast. The evidence for the association of oestrogen treatment with carcinoma of the endometrium and that intermittent progestogen treatment reduces the risk of malignant change may be stronger. Purely on analogy therefore it would seem sensible to prescribe some form of progestogen as well as oestrogen. It is unlikely to do harm and may be valuable. Vessey et $a l^{1}$ have shown that the combined contraceptive pill does not increase the risk of breast cancer and may reduce the problems of benign breast disease. Perhaps this patient could have a trial of the combined contraceptive pill with which the prescriber is most familiar. Alternatively, Premarin might be continued for three weeks followed by one week on medroxyprogesterone or norethisterone. Such patients may need varying therapeutic trials in an effort to give them maximum relief. Details of drugs available are to be found in $M I M S$, and a guide to the clinical pharmacology of progesterone is in a recent book. ${ }^{2}$

1 Vessey, M P, Doll, R, and Jones, K, Lancet, 1975, 1, 941. Macdonald, R R, in Scientific Basis of Obstetrics and Gynaecology, ed R R Mac-
donald, 2nd edn, p 393. Edinburgh, Churchill Livingstone, 1975 . 